\title{
Erratum: Weyl semimetal phase in the non-centrosymmetric compound TaAs
}

L. X. Yang, Z. K. Liu, Y. Sun, H. Peng, H. F. Yang, T. Zhang, B. Zhou, Y. Zhang, Y. F. Guo, M. Rahn, D. Prabhakaran, Z. Hussain, S.-K. Mo, C. Felser, B. Yan and Y. L. Chen

Nature Physics 11, 509-514 (2015); published online 17 August 2015; corrected after print 3 September 2015.

In the version of this Letter originally published a description of arc-like Fermi surfaces in the abstract contained a typographical error. This error has been corrected in the online versions. 